Article

\title{
Cumulative Exposure to Adverse Childhood Experience: Depressive Symptoms, Suicide Intensions and Suicide Plans among Senior High School Students in Nanchang City of China
}

\author{
Zhihui Jia ${ }^{1,+}{ }^{,}$Xiaotong Wen ${ }^{1,+}{ }^{,}$Feiyu Chen ${ }^{2}$, Hui Zhu ${ }^{3}$, Can Li ${ }^{4}$, Yixiang Lin ${ }^{1}$, Xiaoxu Xie ${ }^{5, *(1)}$ \\ and Zhaokang Yuan $1, *$ \\ 1 School of Public Health, Jiangxi Province Key Laboratory of Preventive Medicine, Nanchang University, \\ Nanchang 330006, China; 401437618004@email.ncu.edu.cn (Z.J.); 406530517824@email.ncu.edu.cn (X.W.); \\ linyixiang338@163.com (Y.L.) \\ 2 Center for Disease Control and Prevention, Dongxiang District, Fuzhou 331800, China; dxaids@163.com \\ 3 Jiangxi Province Center for Disease Control and Prevention, Nanchang 330006, China; ncuzhuhui@126.com \\ 4 Queen Mary School, Nanchang University, Nanchang 330006, China; can.li@se16.qmul.ac.uk \\ 5 School of Public Health, Fujian Medical University, Fuzhou 350000, China \\ * Correspondence: xiexiaoxu@aliyun.com (X.X.); yuanzhaokang@ncu.edu.cn (Z.Y.); \\ Tel.: +86-150-7000-9709 (X.X.); +86-135-7693-5811 (Z.Y.) \\ + These authors contributed equally to this study.
}

Received: 3 June 2020; Accepted: 24 June 2020; Published: 30 June 2020

\begin{abstract}
This study tested relationships between different types of adverse childhood experiences (ACE) and depressive symptoms, suicide intensions, suicide plans and examines the cumulative effects of adverse childhood experience on depressive, suicide intentions and suicide plans among senior high school students. We conducted a survey among five senior high schools in Nanchang city, which were selected through stratified random cluster sampling. Among the 884 respondents, 409 were male $(46.27 \%)$, and 475 were female (53.73\%); the age ranged from 14 to 18 . During the past 12 months, $199(22.51 \%)$ students presented to depressive symptoms, $125(14.14 \%)$ students had suicide intensions, $55(6.22 \%)$ students had suicide plans. As ACE scores increased, there was an increase in the odds of (1) depressive symptoms-one ACE (adjusted odds ratio, AOR $=2.096$, $p<0.001$ ), two ACEs (AOR = 3.155, $p<0.001$ ) and three to five ACEs (AOR = 9.707, $p<0.001$ ); suicide intensions-1 ACE (AOR = 1.831, $p=0.011$ ), two ACEs (AOR = 2.632, $p=0.002$ ) and three to five ACEs (AOR $=10.836, p<0.001)$; and (2) suicide plans-one ACE (AOR $=2.599, p<0.001)$, two ACEs $(\mathrm{AOR}=4.748, p<0.001)$ and three to five ACEs (AOR $=22.660, p<0.001)$. We should increase the awareness of adolescents who have had adverse childhood experience, especially those with multiple ACEs to prevent depression and suicide among senior high school students.
\end{abstract}

Keywords: adverse childhood experience; depressive symptoms; suicide intensions; suicide plans

\section{Introduction}

Adverse childhood experiences (ACEs) can be defined as negative events experienced by an individual during his childhood, which will cause harm and threat to his psychological and physical health [1-3]. Negative events including such events as parental substance misuse and mental disorder, sexual abuse, physical abuse, emotional abuse, physical neglect, emotional neglect, familial death, parental separation, residential instability and witnessing violence in the home [4-8]. Adverse childhood experiences is a severe public health problem worldwide, imposing huge socioeconomic 
burdens and increasing affected individuals' risk of mental disorders, including depressive symptoms and suicidal behaviors [9-11].

ACEs are very prevalent. Overall, $35.4 \%$ had one or more ACEs, according to the Minnesota Survey, which is a large $(n=105,759)$, statewide, anonymous survey of public high school students [12]. Based on the meta-analysis of 47 studies, the results estimated prevalence for Chinese child physical abuse was $36.6 \%$ [13]. In China, a systematic review estimated that among various types of abuse, physical abuse was the most prevalent (reported to be $26.6 \%)$, followed by neglect $(26.0 \%)$, emotional abuse (19.6\%) and sexual abuse (8.7\%) [14].

In several studies, adverse childhood experiences have shown a significant association with depressive symptoms and suicidal behavior. Suicide is an ancient and cross-cultural theme and remains a public health problem worldwide [14]. Suicide ideations and plans were essential precursors of suicide and had a globally lifetime prevalence of $9.2 \%$ and $3.1 \%$, respectively. Of American high school students, $17.2 \%$ had suicide ideation during the past 12 months according to youth risk behavior survey (YRBS) conduct by the Centers for Disease Control (CDC) of the United States [15]. According to the survey, $13.6 \%$ of high school students nationwide had suicide planning [15]. Over one million high school students in the United States are treated by a nurse or doctor annually for a suicide attempt [15]. According to the prior research findings described, we found that different types of adverse childhood experiences would increase the risk of suicidal behavior and have different extended effects on this behavior [16].

Children are often exposed to multiple forms of abuse and household dysfunction. There is evidence that cumulative exposure to adversities may have more significant impact on health outcomes than individual stressors. However, the co-occurrence of multiple ACEs is common, to the best of our knowledge, several prior studies had examined clusters of ACEs that can be identified as more closely related to suicidal behavior. However, adverse childhood experiences are known risk factors for suicidal behavior, we do not know the coexistence of these factors increases the risk. To best understand the impact of adversity in childhood, it is essential to consider this co-occurrence [17].

Recognition of the high co-occurrence of adversities led to the cumulative-risk approach widely used. This approach tallies the number of adversities experienced to create a risk score [18]. The cumulative-risk approach has been widely adopted and has proved useful for highlighting the public-health importance of adverse childhood experiences [17].

This study tested relationships between different types of ACEs and depressive, suicide intensions, suicide plans for senior high school students in Nanchang city, which is the capital city of Jiangxi province in China. Moreover, then, this study examines the cumulative exposure to adverse childhood experience and its influencing on depressive, suicide intentions and suicide plans among senior high school students.

\section{Materials and Methods}

\subsection{Design}

The study was designed to monitor health-related behaviors among high-school students. Our questionnaire was adapted from the youth risk behavior surveillance system (YRBSS), a public health project initiated by the US Centers for Disease Control and Prevention in 1989 to monitor major health hazards that cause deaths, illnesses and various social problems in high school students. Its questionnaire was used as the template for our study at five large public high schools in Nanchang city of Jiangxi Province, China. We modified the questionnaire so that it could be more suitable for this study, and the questionnaire was proved to be reliable and valid. The survey was conducted in May 2015, and the data collected were used in this study. 


\subsection{Participants}

In May 2015, we surveyed among senior high school students attending five senior high schools in Nanchang city, and the schools were selected through stratified random cluster sampling. All the 34 senior high schools in Nanchang city were ranked from high to low according to their cutoff scores for the senior high school entrance examination. Sophomores and juniors in each school were included. The cumulative number of students in order reached 21,660 and a sampling interval of 4332 was produced by dividing the total number of students by five. Meanwhile, a random number of 2453, which was smaller than the sampling interval, was obtained from the random number table. The school in which the cumulative number of students corresponds to the random number is the first selected school. Then, a new random number was generated by adding this random number to the sampling interval. Similarly, the school with the corresponding number of students is the second selected school. In this way, five schools were selected. In each school, two grade 10 classes and two grade 11 classes were selected in the same way, and all the students in each class were investigated. A total of 950 questionnaires were distributed, and 884 questionnaires were collected. The effective rate of the questionnaire was $93.05 \%$.

The students were instructed by previously trained investigators, who were postgraduate students majored in public health and preventive medicine at Nanchang University and the University of Nevada. They assisted the investigation process by explaining the purpose and content of the survey to the respondents, clarifying the specific requirements of the questionnaire, explaining the precautions, and dispelling the doubts of the respondent. Eventually, they obtained the trust of the respondents. Meanwhile, all students were informed that their responses would be anonymous as the questionnaires did not involve any collection of personal information. The questions asking about the students' background would only be used to investigate the types of students completing this survey. The students were also informed about the importance of honesty and were told that their answers would not affect their grades at school. It took the students $45 \mathrm{~min}$ to complete the Chinese version questionnaires independently as required.

Among the 884 respondents, 409 were male (46.27\%) and 475 were female (53.73\%); the age ranged from 14 to 18 years, including 128 (14.48\%) aged 15 years old or younger, 385 (43.55\%) aged 16 years old, and $371(41.97 \%)$ aged 17 years old or older.

\subsection{Exposure Variable}

\subsubsection{Adverse Childhood Experiences}

This survey includes a measure of lifetime sexual abuse: "Have you ever been physically forced to have sexual intercourse when you did not want to?" Additionally, four variables were adapted from the behavioral risk factor surveillance system (BRFSS) ACE module [19-21] to assess the lifetime prevalence of (1) sexual abuse- "Have you ever been forced to have sexual intercourse when you did not want to?"; (2) physical abuse by an adult-“Have you ever been hit, beaten, kicked or physically hurt in any way by an adult? (Do not include being spanked for bad behavior)"; (3) household domestic violence- "Have you ever seen or heard adults in your home slap, hit, kick, punch or beat each other up?"; (4) household mental illness-“"Have you ever lived with someone who was depressed, mentally ill or suicidal?"; and (5) household substance abuse-"Have you ever lived with someone who was a problem drinker or alcoholic or abused street or prescription drugs?" Responses to all ACE questions were dichotomized as yes versus no. The five ACE questions were summed to create a total ACE score (range 0-5). The ACE score was further categorized as 0, 1, 2 and 3-5 ACEs.

\subsubsection{Covariates}

Demographic characteristics included sex, age and school type. The students were divided into three age groups, including 15 years old and younger, 16 years old, 17 years old, and and 
older. Moreover, school types were key senior high school, general senior high school and art senior high school.

\subsection{Outcome Variable}

\subsubsection{Depressive Symptoms}

Depressive symptoms were assessed with a standardized question from the CDC YRBS: "During the past 12 months, did you ever feel so sad or hopeless almost every day for two weeks or more in a row that you stopped doing some usual activities?" The response choices were dichotomized as yes vs. no.

\subsubsection{Suicide Intensions}

A standardized YRBS question was used to assess suicide intentions, "During the past 12 months, did you ever seriously consider attempting suicide?" Responses were dichotomized as yes versus no.

\subsubsection{Suicide Plans}

Suicide attempts were assessed by asking students, "During the past 12 months, did you make a plan about how you would attempt suicide?" Responses were dichotomized as yes versus no.

\subsection{Analyses}

Epi Data 3.1 software (The Epi Data Association, Odense, Denmark) was used to enter data from two persons and two computers. All analyses were performed using the Statistic Package for Social Science 24.0 (IBM Corporation, Armonk, NY, USA). All statistical tests were two-sided with a significance level of $p<0.05$. The analyses included three steps. First, descriptive statistics were used to summarize sociodemographic characteristics and ACEs of the sample. We used Pearson's chi-square test to compare the incidence rate of depressive symptoms, the incidence rate of suicide intensions, the incidence rate of suicide plans with different sociodemographic factors and ACEs. Second, we assessed the relationship by multiple logistic regression models between sociodemographic factors, adverse childhood experience and depressive symptoms, suicide intensions, suicide plans of 884 Chinese senior high school students. Calculate different factors adjusted odds ratio (AOR) and its 95\% confidence interval (95\% CI). Statistical significance was determined according to the $P$-values. Finally, depressive symptoms, suicide intensions, suicide plans as predictors, we conduct multiple logistic regression models to explore the adverse childhood experience cumulative effect among Chinese senior high school students. AOR, 95\% CI and $p$-value were reported.

\subsection{Ethics Statement}

This study was approved by the medical ethics committee of Nanchang University Institutional Review Board (2014-3-4) and conducted with the informed written consent of the school. Participants and their parents provided informed consent before data collection in a parents' meeting. Students were informed that their participation in the study was voluntary, and their responses were anonymous.

\section{Results}

\subsection{Describe Sociodemographic Characteristics and Adverse Childhood Experience of Sample}

Table 1 first describes students' sociodemographic characteristics and ACEs. Among the 884 respondents, 409 were male $(46.27 \%), 475$ were female (53.73\%); the age ranged from 14 to 18 years, including $128(14.48 \%)$ aged 15 years old or younger, $385(43.55 \%)$ aged 16 years old, $371(41.97 \%)$ aged 17 years old or older. There are 382 students (43.21\%) in key senior high school, while $392(44.35 \%)$ students in General senior high school and 110 (12.44\%) students in art senior high school. Overall, $5.66 \%$ of the sample experienced sexual abuse, $10.41 \%$ of the sample experienced physical abuse, 
$21.49 \%$ of the sample experienced household domestic, $10.86 \%$ of the sample experienced household mental illness, and $4.75 \%$ of the sample experienced household substance use/abuse.

Table 1. Unadjusted associations of adverse childhood experience, sociodemographic characteristics and depressive symptoms, suicide intensions, suicide plan of 884 Chinese high school students, 2015.

\begin{tabular}{|c|c|c|c|c|c|}
\hline Variables & Total $(N=884)$ & $\begin{array}{c}\text { Depressive Symptoms } \\
n(\%)\end{array}$ & $\begin{array}{c}\text { Suicide Intensions } \\
n(\%)\end{array}$ & $\begin{array}{c}\text { Suicide Plans } \\
n(\%)\end{array}$ & $p$-Value \\
\hline \multicolumn{6}{|l|}{ Sex } \\
\hline Female & $475(53.73)$ & $110(23.16)$ & $70(14.74)$ & $26(5.47)$ & \\
\hline Male & $409(46.27)$ & $89(21.76)$ & $55(13.45)$ & $29(7.09)$ & \\
\hline \multicolumn{6}{|l|}{ Age (year) } \\
\hline$\leq 15$ & $128(14.48)$ & $23(17.97)$ & $13(10.16)$ & $8(6.25)$ & \\
\hline 16 & $385(43.55)$ & $93(24.16)$ & $61(15.84)$ & $21(5.45)$ & \\
\hline$\geq 17$ & $371(41.97)$ & $83(22.37)$ & $51(13.75)$ & $26(7.01)$ & \\
\hline \multicolumn{6}{|l|}{ School } \\
\hline Key senior high school & $382(43.21)$ & $100(26.18)$ & $62(16.23)$ & $30(7.85)$ & A1 \\
\hline General senior high school & $392(44.35)$ & $72(18.37)$ & $45(11.48)$ & $16(4.08)$ & \\
\hline Art senior high school & $110(12.44)$ & $27(24.55)$ & $18(16.36)$ & $9(8.18)$ & \\
\hline Sexual abuse & & & & & A2 B1 C3 \\
\hline No & $834(94.34)$ & $179(21.46)$ & $112(13.43)$ & $43(5.16)$ & \\
\hline Yes & $50(5.66)$ & $20(40.00)$ & $37(74.00)$ & $12(24.00)$ & \\
\hline Physical abuse & & & & & A3 B3 C3 \\
\hline No & $792(89.59)$ & $155(19.57)$ & $94(11.87)$ & $35(4.42)$ & \\
\hline Yes & $92(10.41)$ & $44(47.83)$ & $31(33.70)$ & $20(21.74)$ & \\
\hline Household domestic violence & & & & & A3 B3 C2 \\
\hline No & $694(78.51)$ & $133(19.16)$ & $83(11.96)$ & $35(5.04)$ & \\
\hline Yes & $190(21.49)$ & $66(34.74)$ & $42(22.11)$ & $20(10.53)$ & \\
\hline Household mental illness & & & & & A3 B3 C3 \\
\hline No & $788(89.14)$ & $153(19.42)$ & $91(11.55)$ & $32(4.06)$ & \\
\hline Yes & $96(10.86)$ & $46(47.92)$ & $34(35.42)$ & $23(23.96)$ & \\
\hline Household substance use/abuse & & & & & A3 B3 C3 \\
\hline No & $842(95.25)$ & $180(21.38)$ & $111(13.18)$ & $43(5.11)$ & \\
\hline Yes & $42(4.75)$ & $19(45.24)$ & $14(33.33)$ & $12(28.57)$ & \\
\hline ACE Score & & & & & A3 B3 C3 \\
\hline 0 & $582(65.84)$ & $93(15.98)$ & $57(9.79)$ & $17(2.92)$ & \\
\hline 1 & $193(21.83)$ & $55(28.50)$ & $32(16.58)$ & $14(7.25)$ & \\
\hline 2 & $72(8.14)$ & $27(37.50)$ & $16(22.22)$ & $9(12.50)$ & \\
\hline $3-5$ & $37(4.19)$ & $24(64.86)$ & $20(54.05)$ & $15(40.54)$ & \\
\hline Total & $884(100.00)$ & $199(22.51)$ & $125(14.14)$ & $55(6.22)$ & - \\
\hline
\end{tabular}

Note: $\mathrm{AOR}=$ adjusted odds ratio; $\mathrm{CI}=$ confidence interval; ref $=$ reference. $\mathrm{A}$ : depressive symptoms, $\mathrm{A} 1<0.05$; A2 < 0.01; A3 < 0.001; B: suicide intensions, B1 < 0.05; B2 < 0.01; B3 < 0.001; C: suicide plan, C1 < 0.05; C2 <0.01; C $3<0.001$.

In this survey, 884 records were used. During the past 12 months, 199 (22.51\%) students presented to depressive symptoms. During the past 12 months, 125 (14.14\%) students had suicide intensions, $55(6.22 \%)$ students had suicide plans.

\subsection{Describe the Incidence rate of Depressive Symptoms, Suicide Intentions and Suicide Plans}

As shown in Table 1, the incidence rate of depressive symptoms always higher than the incidence rate of suicide intensions among groups with different characteristics. Similarly, the incidence rate of suicide intensions always higher than the incidence rate of suicide plans among groups with different characteristics.

No statistically significant differences were detected regarding the gender, age among depressive symptoms, suicide intensions, suicide plans. However, the incidence rate of depressive symptoms was statistically significant difference among different school type groups $(p<0.05)$.

Table 1 also shows the unadjusted associations between different adverse childhood experience type groups and depressive symptoms, suicide intensions, suicide plans. The incidence rate of depressive symptoms, the incidence rate of suicide intensions, the incidence rate of suicide plans of students was statistically significant different between individual ACEs (all $p<0.01$ ). 
The incidence rate of depressive symptoms of students were statistically significant different among different ACE scores groups, such as sexual abuse $\left(\chi^{2}=9.292, p=0.002\right)$, physical abuse $\left(\chi^{2}=37.725, \mathrm{p}<0.001\right)$, household domestic $\left(\chi^{2}=20.737, p<0.001\right)$, household mental illness $\left(\chi^{2}=39.848, \mathrm{p}<0.001\right)$, household substance use/abuse $\left(\chi^{2}=13.056, p<0.001\right)$.

The incidence rate of suicide intensions of students was statistically significant difference among different ACE scores groups (all $p<0.05$ ). The incidence rate of suicide plans of students was statistically significant difference among different ACE scores groups (all $p<0.01$ ) (Table 1 ).

\subsection{Associations of Adverse Childhood Experience and Depressive Symptoms, SUICIDE intensions, Suicide Plans}

After controlling for all covariates, logistic regression models showed that higher odds of depressive symptoms were discovered among students who experienced physical abuse $(\mathrm{OR}=2.621)$, household domestic $(\mathrm{OR}=1.530)$ or household mental illness $(\mathrm{OR}=2.789)$.

Logistic regression analyzed that higher odds of suicide intentions were found among students who experienced physical abuse $(\mathrm{OR}=2.723)$ or household mental illness $(\mathrm{OR}=3.153)$ under controlling for all covariates.

Logistic regression result displayed that after controlling for all covariates, higher odds of suicide plans were observed among students who experienced sexual abuse $(\mathrm{OR}=2.894)$, physical abuse $(\mathrm{OR}=3.189)$ or household mental illness $(\mathrm{OR}=4.288)$. The results were shown in Table 2.

Table 2. Adjusted associations of adverse childhood experience and sociodemographic characteristics with depressive symptoms, suicide intensions and suicide plans of 884 Chinese high school students, 2015 AOR (95\% CI).

\begin{tabular}{|c|c|c|c|c|}
\hline Variables & Depressive Symptoms & Suicide Intensions & Suicide Plans & $p$-Value \\
\hline \multicolumn{5}{|l|}{ Sex } \\
\hline Female (ref) & 1 & 1 & 1 & \\
\hline Male & $0.779(0.553,1.097)$ & $0.743(0.491,1.122)$ & $0.920(0.493,1.715)$ & \\
\hline \multicolumn{5}{|l|}{ Age } \\
\hline$\leq 15$ year $(\mathrm{ref})$ & 1 & 1 & 1 & \\
\hline 16 year & $1.607(0.936,2.759)$ & $1.941(0.989,3.807)$ & $0.956(0.387,2.360)$ & \\
\hline$\geq 17$ year & $1.380(0.798,2.386)$ & $1.489(0.752,2.950)$ & $1.036(0.425,2.522)$ & \\
\hline \multicolumn{5}{|l|}{ School } \\
\hline Key senior high school (ref) & 1 & 1 & 1 & \\
\hline General senior high school & $0.719(0.501,1.031)$ & $0.779(0.504,1.202)$ & $0.607(0.311,1.186)$ & \\
\hline Art senior high school & $0.969(0.574,1.637)$ & $1.065(0.577,1.968)$ & $1.061(0.448,2.516)$ & \\
\hline \multicolumn{5}{|l|}{ Sexual abuse } \\
\hline No (ref) & 1 & 1 & 1 & \\
\hline Yes & $1.565(0.802,3.054)$ & $1.334(0.623,2.858)$ & $2.894(1.210,6.924)$ & $\mathrm{C} 1$ \\
\hline \multicolumn{5}{|l|}{ Physical abuse } \\
\hline No (ref) & 1 & 1 & 1 & \\
\hline Yes & $2.621(1.603,4.285)$ & $2.723(1.581,4.689)$ & $3.189(1.549,6.567)$ & A3 B3 C2 \\
\hline \multicolumn{5}{|l|}{ Household domestic violence } \\
\hline No (ref) & 1 & 1 & 1 & \\
\hline Yes & $1.530(1.034,2.262)$ & $1.347(0.849,2.136)$ & $0.974(0.489,1.938)$ & A1 \\
\hline \multicolumn{5}{|l|}{ Household mental illness } \\
\hline No (ref) & 1 & 1 & 1 & \\
\hline Yes & $2.789(1.703,4.567)$ & $3.153(1.839,5.404)$ & $4.288(2.097,8.766)$ & A3 B3 C2 \\
\hline \multicolumn{5}{|c|}{ Household substance use/abuse } \\
\hline No (ref) & 1 & 1 & 1 & \\
\hline Yes & $1.202(0.570,2.536)$ & $1.231(0.551,2.754)$ & $1.975(0.761,5.125)$ & \\
\hline
\end{tabular}

Note: $\mathrm{AOR}=$ adjusted odds ratio; $\mathrm{CI}=$ confidence interval; ref $=$ reference. $\mathrm{A}$ : depressive symptoms, $\mathrm{A} 1<0.05$; $\mathrm{A} 2<0.01 ; \mathrm{A} 3<0.001 ; \mathrm{B}$ : suicide intensions, $\mathrm{B} 1<0.05 ; \mathrm{B} 2<0.01 ; \mathrm{B} 3<0.001$; : suicide plans, $\mathrm{C} 1<0.05 ; \mathrm{C} 2<0.01$; C $3<0.001$. 
3.4. Associations of ACE Score and Depressive Symptoms, Suicide Intensions, Suicide Plans

After controlling for all covariates, logistic regression models showed that much higher odds of depressive symptoms were discovered among students whose ACE score were much higher. Suicide intentions and planning are similar. As ACE scores increased, there was an increase in the odds of (1) depressive symptoms-1 ACE (AOR = 2.096, $p<0.001), 2$ ACEs (AOR $=3.155, p<0.001$ ) and 3-5 ACEs (AOR = 9.707, $p<0.001)$; suicide intensions-1 ACE (AOR = 1.831, $p=0.011), 2$ ACEs $(\mathrm{AOR}=2.632, p=0.002)$ and $3-5$ ACEs $(\mathrm{AOR}=10.836, p<0.001)$; and (2) suicide plans-1 ACE (AOR = 2.599, $p<0.001), 2$ ACEs (AOR $=4.748, p<0.001$ ) and 3-5 ACEs (AOR $=22.660, p<0.001$ ) (Table 3). Figure 1 showed that the cumulative effect of ACEs on depressive symptoms, suicide intensions, suicide plan.

Table 3. Cumulative effect of ACEs on depressive symptoms, suicide intensions and suicide plans of 884 Chinese high school students-2015.

\begin{tabular}{ccccccc}
\hline \multirow{2}{*}{ ACE Score } & \multicolumn{2}{c}{ Depressive Symptoms } & \multicolumn{2}{c}{ Suicide Intensions } & \multicolumn{2}{c}{ Suicide Plans } \\
\cline { 2 - 7 } & AOR (95\% CI) & $p$-Value & AOR (95\% CI) & $p$-Value & AOR (95\% CI) & $p$-Value \\
\hline 0 (ref) & 1 & - & 1 & - & 1 & - \\
1 & $2.096(1.429$, & $<0.001$ & 1.831 & 0.011 & $(1.256,5.378)$ & 0.010 \\
& $3.074)$ & & $(1.147,2.922)$ & & 4.748 & $<0.001$ \\
2 & $3.155(1.864$, & $<0.001$ & $(1.417,4.888)$ & 0.002 & $(2.032,11.096)$ & \\
$3-5$ & $5.339)$ & & 10.836 & & 22.660 & $<0.001$ \\
& 9.707 & & & & & \\
\end{tabular}

$\mathrm{AOR}=$ adjusted odds ratio; $\mathrm{CI}=$ confidence interval; ref = reference.

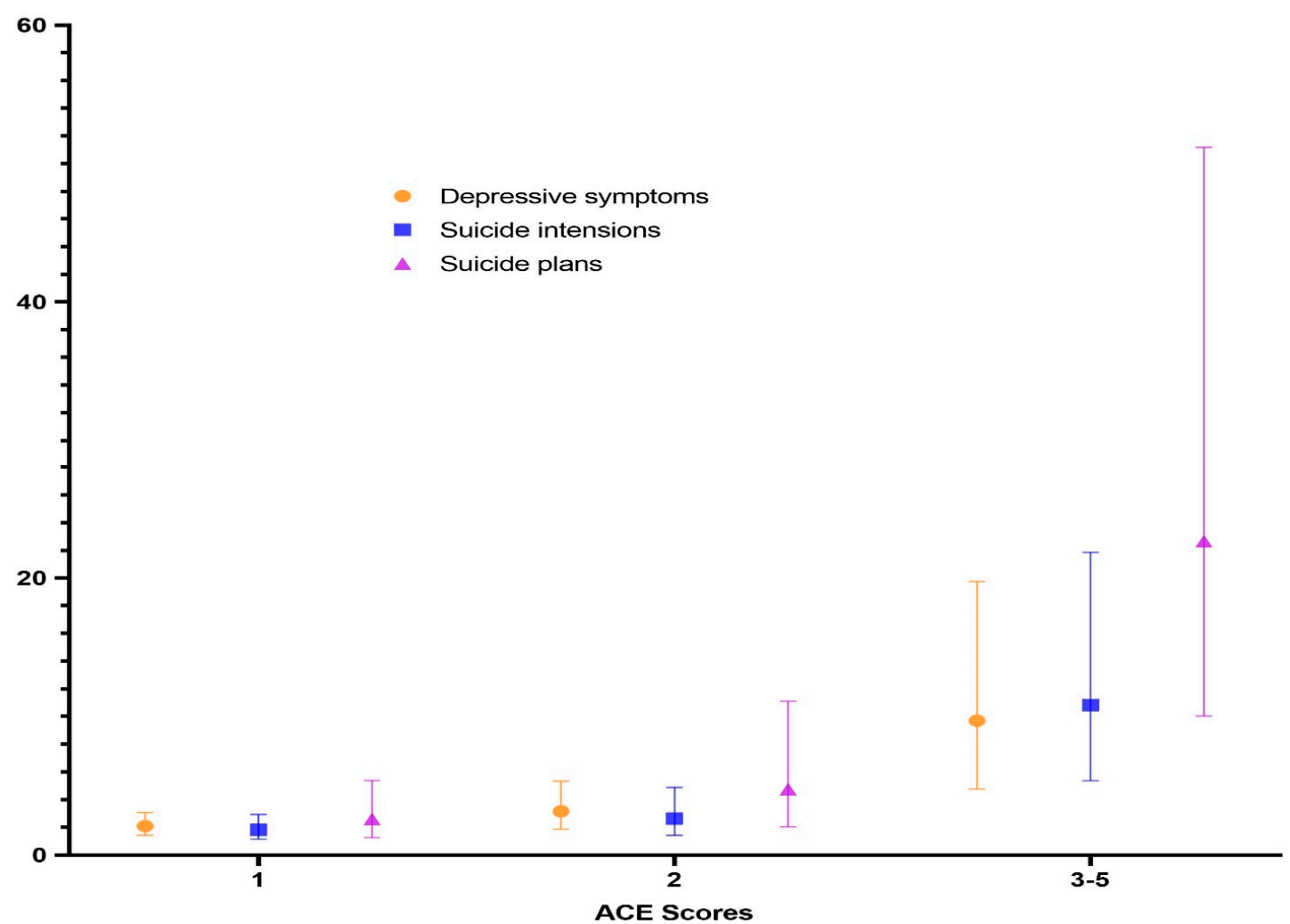

Figure 1. Cumulative effect of ACEs on depressive symptoms, suicide intensions and suicide plans of 884 Chinese high school students. 


\section{Discussion}

This study examined the relationship between each ACEs, including sexual abuse, physical abuse, domestic violence, family mental illness, family substance abuse and three outcome variables: depression, suicide intentions and suicide plans. However, we found that $34.16 \%$ of the sample self-reported at least exposure to one type of ACEs, which was low compared with the previous studies. It is possible that only five variables were used as the ACE index in our study, which referred to the behavioral risk factor surveillance system (BRFSS). Previous studies may take more variables as ACE index, such as Remy M selected parental divorce [22], and Tracie O. Afifi utilized expanded ACE index that included spanking [23].

Of students, $22.5 \%$ reported depressive symptoms in this study, which is slightly lower than $24.3 \%$ among Chinese adolescents (2018 years) [24]. Relevant studies have shown that the prevalence of depressive symptoms among Chinese adolescents was very likely higher than those in other countries [25-27]. Tremendous academic pressure may account for the high prevalence of depression in Chinese adolescents [28]. Our study also found that differences in depressive symptoms among students in three types of schools were statistically significant, which may be caused by the differences in academic pressure. In addition, interpersonal pressure and specific cultural factors may also lead to depression [24].

Suicide intentions and plans were reported at $6.9 \%$ and $4.0 \%$ in a recent study of Spanish adolescents [4]. Similarly, it was also found that at least $4.2 \%$ of adolescents planned to suicide in a study among 15,191 sample adolescents in the United States [8]. Suicide is a leading cause to death for adolescents in Australia [29]. However, only 5.5\% and 2.9\% suicide behaviors were also reported in the Australian survey of 12- to 17-year-olds [30]. Suicide intentions and plans accounted for $17.7 \%$ and $7.3 \%$ in mainland China, and there are $14.1 \%$ attempted suicide and $6.2 \%$ planed among adolescents in this study, which is higher than other countries [31]. One important reason is that there are more than 68 million left-behind children in China [32], and they are more susceptible to being victimized by discrimination, humiliation and bullying [33], causing suicide [34,35]. Moreover, academic pressure accounts for the first place (45.5\%) among the causes of suicide in Chinese adolescents.

Adolescents are key objects of protection in the field of public health. The results showed that ACEs were important determinants of chronic physical problems in adolescents [36-38]. Our study aimed to provide suggestions on how to promote adolescent health better. However, previous studies used retrospective design to examine the relationship between adverse childhood experiences and outcomes in adulthood, which interval time was too long to recall accurately [39]. In other words, our study surveyed high school students and reduced error and bias.

The results indicated that each type of ACEs was significantly associated with depressive symptoms, suicide intentions and suicide plans. According to statistics, one-fifth of girls in the world are subject to sexual abuse [40]. Our tentative results found that depressive symptoms, suicide intentions, and suicide plans were associated with sexual abuse. In adjusted models, people who reported sexual and physical abuse had an increased risk of suicide plans, which is consistent with an Israeli study [41]. There was also a correlation between sexual abuse and depressive symptoms. Physical and sexual abuse victims in childhood were at increased risk of depression, anxiety, and post-traumatic stress disorder (PTSD) in adulthood [42]. Children suffered in the process of mature experience, which is the critical risk factors of depression [43]. Furthermore, previous research showed that male who experienced sexual abuse in childhood had higher levels of depressive symptoms after 50 years old, and the exposure time of the study samples' depression symptoms may be delayed [44].

Physical abuse also is a risk factor for depressive symptoms, suicide intentions and suicide plans. Compared to students with no physical abuse, individuals who suffered physical abuse had 2.73, 2.72, 3.19 times increased odds of reporting depressive symptoms, suicide intentions and suicide plans. Inbar Kremer also said, such as physical abuse victims more attractive to death [41]. One study estimated that a quarter of children had experienced physical abuse worldwide [45]. Chromosomal and functional brain damage [46-48], proximal behavioral problems [49] and misconduct [42] are all 
associated with physical abuse throughout life [50]. Compared with emotional abuse, it is relatively easy to identify physical abuse and sexual abuse in the clinical environment because the latter two have more apparent signs [51]. Therefore, we should give full play to the important role of controlling physical abuse and sexual abuse in reducing bad behaviors in high school students.

Family mental illness is a risk factor for depressive symptoms, suicide intentions and suicide plans. Compared to students with no FMI, individuals reporting the ACE had 2.79 ime-increased odds of reporting depressive symptoms, 3.15 times increased odds of attempting suicide, 4.29 times increased odds of reporting suicide plans during childhood. A classic review has found that parental psychopathology, such as substance abuse, depression or antisocial behavior, is the most important predictor of adolescent suicide [13].

Household violence is a risk factor for depression, and high school students who experienced domestic violence had a 1.53-fold increase in depressive symptoms. No country is immune to the problem of violence, including domestic violence, the consequences of which can be devastating [52]. There are gender differences in sexual abuse, physical abuse and household violence in childhood and female are vulnerable groups [53], which reminds us to pay more attention to the mental health of women.

In addition to all this, our results align with previous research to identify that a general dose-response relationship between ACE score and adult behavior results [54-56]. As the ACE score increased, the odds of experiencing depressive symptoms, suicide attempts and suicide plans in adulthood also increased. Take depression symptoms as an example, compared to individuals with no ACEs, students reporting one ACE had 2.10 times increased odds, two ACEs had 3.16 times increased odds and three or more ACEs had 9.70 times increased odds, Which are consistent with those of previous studies on the correlation between ACES and adverse behavior outcomes [57].

\section{Limitations}

The severity, frequency and time of ACE factors were not included in the study. In addition, our study concluded that as ACEs scores increased, the probability of occurrence of the outcomes went up, and each increment of adversity would increase the occurrence. Nevertheless, the relationship between ACEs and ACEs, whether the occurrence of one kind of ACEs increases the probability of another, for example, Michael T proposed that once per young person is exposed to one kind of ACEs, the probability of another kind of ACEs increased 1286 times [58], was not designed in this study. It has to be said that the scope of our study ACE indicators is not wide enough, the exposure and results may be low, and there is an outcome bias. Self-reported tests of children's adverse experiences and outcome variables may bias and reduce actual prevalence.

\section{Conclusions}

To our knowledge, this is one of the few studies to explore the relationships between adolescents' adverse experiences and their psychosocial behavioral health in a representative sample of senior high school students. In this study, we compared the data with other countries and found that the depressive symptoms and suicidal behaviors of Chinese adolescents were relatively severe. On this basis, we analyzed the effects of each ACE and the cumulative ACE scores on the health outcomes of high school students. First, we found many adverse experiences are risk factors for depression and suicidal behaviors in adolescents; second, we confirmed that there was a dose-response relationship between ACEs and depressive symptoms and suicide intentions and plans. Therefore, we should focus on starting at the source to prevent depression and suicide among high school students, increasing the attention to adolescents who had adverse experiences, especially those with the multiple, and playing an important role in controlling key risk factors in the protection of adolescent health. Further studies will be necessary to explore the influence of different characteristics of ACEs on outcomes and study the relationship between ACEs. 
Author Contributions: Conceptualization, X.X. and Z.Y.; data curation, X.W. and Z.J.; formal analysis, Z.J., X.W., F.C., H.Z., Y.L.; funding acquisition, X.X. and Z.Y.; investigation, Z.J., X.W. and H.Z.; methodology, X.W. and Z.J.; project administration, X.X. and Z.Y.; supervision, X.X. and Z.Y.; writing-original draft, X.W. and Z.J.; writing-review \& editing: X.W. and Z.J. and C.L.; All authors have read and agreed to the published version of the manuscript.

Funding: The author(s) disclosed receipt of the following financial support for the research, authorship, and/or publication of this article: This work was supported by Fujian Medical University talent research funding [grant Number: XRCZX2019031] and the Health and Family Planning Commission of Jiangxi Province [grant Number: JXWJWLR111] and Health and Family Planning Commission of Jiangxi Province [grant Number: 00019126].

Acknowledgments: The lead agency of this study is the School of Public Health, Nanchang University, Jiangxi Province Key Laboratory of Preventive Medicine. We would like to express our great appreciation to the collaborating agencies, including Jiangxi Provincial Health Committee, Center of Disease Control and Prevention, Ministry of Education. We also like to thank all the teachers and students who took part in the research design and the field investigation.

Conflicts of Interest: The authors declare no conflicts of interest.

\section{References}

1. Boullier, M.; Blair, M. Adverse childhood experiences. Paediatr. Child Health 2018, 28, 132-137. [CrossRef]

2. Turney, K. Adverse childhood experiences among children of incarcerated parents. Child. Youth Serv. Rev. 2018, 89, 218-225. [CrossRef]

3. Vincent, J.; Felitti, R.F.A.; Nordenberg, D.; David, F.; Williamson, A.M.; Spitz, V.E.; Mary, P.; Koss, J.; Marks, S. Relationship of childhood abuse and household dysfunction to many of the leading causes of death in adults-the adverse childhood experiences (ace) study. Am. J. Prev. Med. 1998, 14, 13.

4. Bjorkenstam, E.; Bjorkenstam, C.; Jablonska, B.; Kosidou, K. Cumulative exposure to childhood adversity, and treated attention deficit/hyperactivity disorder: A cohort study of 543,650 adolescents and young adults in sweden. Psychol. Med. 2018, 48, 498-507. [CrossRef] [PubMed]

5. Zatti, C.; Rosa, V.; Barros, A.; Valdivia, L.; Calegaro, V.C.; Freitas, L.H.; Cereser, K.M.M.; da Rocha, N.S.; Bastos, A.G.; Schuch, F.B. Childhood trauma and suicide attempt: A meta-analysis of longitudinal studies from the last decade. Psychiatry Res. 2017, 256, 353-358. [CrossRef] [PubMed]

6. Angst, J.; Hengartner, M.P.; Rogers, J.; Schnyder, U.; Steinhausen, H.C.; Ajdacic-Gross, V.; Rossler, W. Suicidality in the prospective zurich study: Prevalence, risk factors and gender. Eur. Arch. Psychiatry Clin. Neurosci. 2014, 264, 557-565. [CrossRef]

7. Anda, R.F.; Croft, J.B.; Felitti, V.J.; Nordenberg, D.; Giles, W.H.; Williamson, D.F.; Giovino, G.A. Adverse childhood experiences and smoking during adolescence and adulthood. JAMA J. Am. Med. Assoc. 1999, 282, 1652-1658. [CrossRef] [PubMed]

8. Su, P.-Y.; Han, A.Z.; Wang, G.-F.; Wang, L.-H.; Zhang, G.-B.; Xu, N.; Xu, G. Is childhood maltreatment associated with murderous ideation and behaviors in adolescents in China? Psychiatry Res. 2018, 270, 467-473. [CrossRef]

9. Holshausen, K.; Bowie, C.R.; Harkness, K.L. The relation of childhood maltreatment to psychotic symptoms in adolescents and young adults with depression. J. Clin. Child. Adolesc. Psychol. 2016, 45, $241-247$. [CrossRef]

10. Afifi, T.O.; Taillieu, T.; Zamorski, M.A.; Turner, S.; Cheung, K.; Sareen, J. Association of child abuse exposure with suicidal ideation, suicide plans, and suicide attempts in military personnel and the general population in Canada. JAMA Psychiatry 2016, 73, 229-238. [CrossRef]

11. Chang, J.J.; Tabet, M.; Elder, K.; Kiel, D.W.; Flick, L.H. Racial/ethnic differences in the correlates of mental health services use among pregnant women with depressive symptoms. Matern. Child Health J. 2016, 20, 1911-1922. [CrossRef] [PubMed]

12. Davis, L.; Barnes, A.J.; Gross, A.C.; Ryder, J.R.; Shlafer, R.J. Adverse childhood experiences and weight status among adolescents. J. Pediatr. 2019, 78, 124-137. [CrossRef] [PubMed]

13. Ji, K.; Finkelhor, D. A meta-analysis of child physical abuse prevalence in china. Child Abus. Negl. 2015, 43, 61-72. [CrossRef] [PubMed]

14. Fang, X.M.; Fry, D.A.; Ji, K.; Finkelhor, D.; Chen, J.Q.; Lannen, P.; Dunne, M.P. The burden of child maltreatment in China: A systematic review. Bull. World Health Organ. 2015, 93, 176C-185C. [CrossRef] 
15. Laura Kann, T.M.; William, A.; Harris Shari, L.; Shanklin, K.H.; Flint, B.; Queen, R.L.; Chyen, D. Youth risk behavior surveillance-United States, 2017. Morb. Mortal. Wkly. Rep. 2018, 67, 6-26.

16. Liu, J.B.; Fang, Y.M.; Gong, J.B.; Cui, X.L.; Meng, T.T.; Xiao, B.; He, Y.Q.; Shen, Y.M.; Luo, X.R. Associations between suicidal behavior and childhood abuse and neglect: A meta-analysis. J. Affect. Disord. 2017, 220, 147-155. [CrossRef] [PubMed]

17. McLaughlin, K.A.; Sheridan, M.A. Beyond cumulative risk: A dimensional approach to childhood adversity. Curr. Dir. Psychol. 2016, 25, 239-245. [CrossRef] [PubMed]

18. Evans, G.W.; Li, D.; Whipple, S.S. Cumulative risk and child development. Psychol. Bull. 2013, 139, 1342. [CrossRef]

19. Merrick, M.T.; Ford, D.C.; Ports, K.A.; Guinn, A.S. Prevalence of adverse childhood experiences from the 2011-2014 behavioral risk factor surveillance system in 23 states. JAMA Pediatr. 2018, 172, 1038-1044. [CrossRef] [PubMed]

20. Nelson, D.E.; Holtzman, D.; Bolen, J.; Stanwyck, C.A.; Mack, K.A. Reliability and validity of measures from the behavioral risk factor surveillance system (brfss). Sozial- und Praventivmedizin. 2001, 46, S3-S42.

21. Nelson, D.E.; Powell-Griner, E.; Town, M.; Kovar, M.G. A comparison of national estimates from the national health interview survey and the behavioral risk factor surveillance system. Am. J. Public Health 2003, 93, 1335-1341. [CrossRef] [PubMed]

22. Vink, R.M.; van Dommelen, P.; van der Pal, S.M.; Eekhout, I.; Pannebakker, F.D.; Klein Velderman, M.; Haagmans, M.; Mulder, T.; Dekker, M. Self-Reported adverse childhood experiences and quality of life among children in the two last grades of dutch elementary education. Child Abus. Negl. 2019, 95, 104051. [CrossRef] [PubMed]

23. Afifi, T.O.; Ford, D.; Gershoff, E.T.; Merrick, M.; Grogan-Kaylor, A.; Ports, K.A.; MacMillan, H.L.; Holden, G.W.; Taylor, C.A.; Lee, S.J.; et al. Spanking and adult mental health impairment: The case for the designation of spanking as an adverse childhood experience. Child Abus. Negl. 2017, 71, 24-31. [CrossRef] [PubMed]

24. Tang, X.F.; Tang, S.Q.; Ren, Z.H.; Wong, D.F.K. Prevalence of depressive symptoms among adolescents in secondary school in mainland china: A systematic review and meta-analysis. J. Affect. Disord. 2019, 245, 498-507. [CrossRef]

25. Bond, L.; Toumbourou, J.W.; Thomas, L.; Catalano, R.F.; Patton, G. Individual, family, school, and community risk and protective factors for depressive symptoms in adolescents: A comparison of risk profiles for substance use and depressive symptoms. Prev. Sci. 2005, 6, 73-88. [CrossRef]

26. Murshid, N.S. Parents, friends, and depression: A multi-country study of adolescents in south Asia. Child. Youth Serv. Rev. 2017, 79, 160-165. [CrossRef]

27. Liu, Y.; Lu, Z. Chinese high school students' academic stress and depressive symptoms: Gender and school climate as moderators. Stress Health 2012, 28, 340-346. [CrossRef]

28. Tepper, P.; Liu, X.; Guo, C.; Zhai, J.; Liu, T.; Li, C. Depressive symptoms in Chinese children and adolescents: Parent, teacher, and self reports. J. Affect. Disord. 2008, 111, 291-298. [CrossRef]

29. Kinchin, I.; Doran, C.M. The cost of youth suicide in Australia. Int. J. Environ. Res. Public Health 2018, 15, 672. [CrossRef]

30. Kyron, M.J.; Carrington-Jones, P.; Page, A.C.; Bartlett, J.; Lawrence, D. Factors differentiating adolescents who consider suicide and those who attempt: Results from a national survey of Australian adolescents. Aust. J. Psychol. 2020, 72, 145-155. [CrossRef]

31. Dong, Y.H.; Liu, Y.; Liu, L.; He, W.; Peng, G.H.; Yin, Y.Z.; Chen, T.; Mo, X.Q. Reported rate of suicide-related behaviors among Chinese adolescents: A meta-analysis. Chin. J. Sch. Health 2014, 35, 532-536.

32. Duan, C.R.; Lv, L.D.; Guo, J.; Wang, Z.P. Survival and development of left-behind children in rural china: Based on the analysis of sixth census data. Popul. J. 2013, 199, 37-49.

33. Ge, Y.; Song, L.; Clancy, R.F.; Qin, Y.L. Studies on left-behind children in China: Reviewing paradigm shifts. In Child and Adolescent Development in China; Liu, Y., Grigorenko, E.L., Eds.; Wiley Periodicals: San Francisco, CA, USA, 2019; Volume 163, pp. 115-135.

34. Fellmeth, G.; Rose-Clarke, K.; Zhao, C.Y.; Busert, L.K.; Zheng, Y.T.; Massazza, A.; Sonmez, H.; Eder, B.; Blewitt, A.; Lertgrai, W.; et al. Health impacts of parental migration on left-behind children and adolescents: A systematic review and meta-analysis. Lancet 2018, 392, 2567-2582. [CrossRef] 
35. Lu, R.; Zhou, Y.; Wu, Q.; Peng, X.; Dong, J.; Zhu, Z.; Xu, W. The effects of mindfulness training on suicide ideation among left-behind children in China: A randomized controlled trial. Child Care Health Dev. 2019, 45, 371-379. [CrossRef]

36. Mark, A.; Bellis, K.H.; Leckenby, N.; Perkins, C.; Lowey, H. National household survey of adverse childhood experiences and their relationship with resilience to health-harming behaviors in England. BMC Med. 2014, 12,72 .

37. Kerker, B.D.; Zhang, J.; Nadeem, E.; Stein, R.E.; Hurlburt, M.S.; Heneghan, A.; Landsverk, J.; McCue Horwitz, S. Adverse childhood experiences and mental health, chronic medical conditions, and development in young children. Acad. Pediatr. 2015, 15, 510-517. [CrossRef]

38. Hunt, T.K.A.; Slack, K.S.; Berger, L.M. Adverse childhood experiences and behavioral problems in middle childhood. Child Abus. Negl. 2017, 67, 391-402. [CrossRef]

39. Loria, H.; Caughy, M. Prevalence of adverse childhood experiences in low-income Latino immigrant and nonimmigrant children. J. Pediatr. 2018, 192, 209-215. [CrossRef]

40. Garcia-Moreno, C. Violence against women-International perspectives. Am. J. Prev. Med. 2000, 19, 330-333. [CrossRef]

41. Kremer, I.; Orbach, I.; Rosenbloom, T. Mental pain and suicidal tendencies in sexual and physical abuse victims. Arch. Suicide Res. 2017, 21,307-321. [CrossRef]

42. Adams, J.; Mrug, S.; Knight, D.C. Characteristics of child physical and sexual abuse as predictors of psychopathology. Child Abus. Negl. 2018, 86, 167-177. [CrossRef] [PubMed]

43. Nolen-Hoeksema, S. The role of rumination in depressive disorders and mixed anxiety/depressive symptoms. J.J Abnorm Psychol. 2000, 109, 504-511. [CrossRef]

44. Easton, S.D.; Kong, J.; Gregas, M.C.; Shen, C.; Shafer, K. Child sexual abuse and depression in late life for men: A population-based, longitudinal analysis. J. Gerontol. B Psychol. Sci. Soc. Sci. 2019, 74, 842-852. [CrossRef]

45. Stoltenborgh, M.; Bakermans-Kranenburg, M.J.; Alink, L.R.A.; van Ijzendoorn, M.H. The prevalence of child maltreatment across the globe: Review of a series of meta-analyses. Child Abus. Rev. 2015, 24, 37-50. [CrossRef]

46. Anda, R.F.; Butchart, A.; Felitti, V.J.; Brown, D.W. Building a framework for global surveillance of the public health implications of adverse childhood experiences. Am. J. Prev. Med. 2010, 39, 93-98. [CrossRef] [PubMed]

47. Danese, A.; McEwen, B.S. Adverse childhood experiences, allostasis, allostatic load, and age-related disease. Physiol. Behav. 2012, 106, 29-39. [CrossRef] [PubMed]

48. Cicchetti, D. Annual research review: Resilient functioning in maltreated children-Past, present, and future perspectives. J. Child Psychol. Psychiatry 2013, 54, 402-422. [CrossRef]

49. Bellis, M.A.; Lowey, H.; Leckenby, N.; Hughes, K.; Harrison, D. Adverse childhood experiences: Retrospective study to determine their impact on adult health behaviours and health outcomes in a UK population. J. Public Health 2014, 36, 81-91. [CrossRef]

50. Gomis-Pomares, A.; Villanueva, L. The effect of adverse childhood experiences on deviant and altruistic behavior during emerging adulthood. Psicothema 2020, 32, 33-39.

51. Merricka, M.T.; Ports, K.A.; Ford, D.C.; Afifi, T.O.; Gershoff, E.T.; Grogan-Kaylor, A. Unpacking the impact of adverse childhood experiences on adult mental health. Child Abus. Negl. 2017, 10, 19. [CrossRef]

52. Krug, E.G.; Dahlberg, L.L.; Mercy, J.A.; Zwi, A.B. World Report on Violence and Health; World Health Organization: Geneva, Switzerland, 2002.

53. Haahr-Pedersen, I.; Perera, C.; Hyland, P.; Vallieres, F.; Murphy, D.; Hansen, M.; Spitz, P.; Hansen, P.; Cloitre, M. Females have more complex patterns of childhood adversity: Implications for mental, social, and emotional outcomes in adulthood. Eur. J. Psychotraumatol. 2020, 11, 1708618. [CrossRef]

54. Meinck, F.; Cosma, A.P.; Mikton, C.; Baban, A. Psychometric properties of the adverse childhood experiences abuse short form (ace-asf) among romanian high school students. Child Abus. Negl. 2017, 72, 326-337. [CrossRef] [PubMed]

55. Finkelhor, D.; Shattuck, A.; Turner, H.; Hamby, S. Improving the adverse childhood experiences study scale. JAMA Pediatr. 2013, 167, 70-75. [CrossRef] [PubMed]

56. Balistreri, K.S. Adverse childhood experiences, the medical home, and child well-being. Matern. Child Health J. 2015, 19, 2492-2500. [CrossRef] [PubMed] 
57. Anda, R.F.; Whitfield, C.L.; Felitti, V.J.; Chapman, D.; Edwards, V.J.; Dube, S.R.; Williamson, D.F. Adverse, childhood experiences, alcoholic parents, an later risk of alcoholism and depression. Psychiatr. Serv. 2002, 53, 1001-1009. [CrossRef] [PubMed]

58. Baglivio, M.T.; Epps, N. The interrelatedness of adverse childhood experiences among high-risk juvenile offenders. Youth Violence Juv. Justice 2015, 14, 179-198. [CrossRef]

(C) 2020 by the authors. Licensee MDPI, Basel, Switzerland. This article is an open access article distributed under the terms and conditions of the Creative Commons Attribution (CC BY) license (http://creativecommons.org/licenses/by/4.0/). 